\title{
Variant Anatomy of Hypoglossal Canal: An Osteological Study in North Indian Population
}

\author{
Yadav $\mathbf{S}^{1}$, Pandey $\mathbf{P}^{1}$, Pasricha $\mathbf{N}^{2}$, Bhatnagar $\mathbf{R}^{4}$ \\ ${ }^{1}$ Senior Resident, Department of Anatomy ,Dr Ram Manohar Lohia Institute of Medical Sciences, Lucknow, Uttar Pradesh, India, ${ }^{2}$ Associate Professor: \\ Department of Anatomy, Dr Ram Manohar Lohia Institute of Medical Sciences, Lucknow, Uttar Pradesh, India, ${ }^{3}$ Professor \& Head : Department of \\ Anatomy, Dr Ram Manohar Lohia Institute of Medical Sciences, Lucknow, Uttar Pradesh, India.
}

\section{Abstract}

Introduction: To assess the presence of duplicated hypoglossal canal. Subjects and Methods: A total of 80 dried human skulls were collected from the Anthropology lab of the department of Anatomy K.G.M.U.,U. P., Lucknow, India. The skulls were examined for duplicated hypoglossal canal and presence of posterior condylar canal. Theskulls were closely inspected with the use of hand lens. Results: We observed bilateral duplicated hypoglossal canal in 3 skulls (3.75\%), Unilateral duplication was seen in 15 skulls (18.75\%) [i.e.7 on the right side and 8 on the left side]. We observed that the presence of duplicated hypoglossal canal was mostly associated with the presence of posterior condylar canal. Conclusion: Duplicated hypoglossal canal in humans may result in minor degrees of alterations in the movements of the tongue due to entrapment of nerve during ossification. The clinical relevance of this knowledge is important for radiologists and neurosurgeons.

Keywords: Hypoglossal canal, duplication, skull.

Corresponding Author: Dr. Swati Yadav, Senior Resident, Department of Anatomy, RMLIMS, Lucknow, Uttar Pradesh, India. Email: swatiyadav67@gmail.com

Received: January 2020

Accepted: January 2020

\section{Introduction}

The human skull constitutes the most modified part among the axial skeleton which serves the function of protecting the brain along with the special senses. ${ }^{[1]}$ The hypoglossal canal also known as the anterior condylar canal is the part of occipital bone. It is present deep to each occipital condyle and is directed laterally and slightly forwards. It transmits the hypoglossal nerve, a meningeal branch of ascending pharyngeal artery and emissary vein from basilar plexus. ${ }^{[2]}$ In some instances, a bony spicule divides this canal resulting into double hypoglossal canal. ${ }^{[3,4]}$ The two converging vertebral arteries usually lie medial and ventral to the hypoglossal nerves, and if they are tortuous and deviated laterally may produce pressure upon these nerves. Hypoglossal canal is of great clinical significance in different pathological conditions including fracture of occipital bone, any congenital defect involving posterior part of cranial base or any intra and extra cranial neoplasm. ${ }^{[5-7]}$ Present study is done to report the incidence of variations in hypoglossal canal in North Indian population especially in Uttar Pradesh to make significant conclusion.

\section{Subjects and Methods}

The present study is a cross sectional study which has been carried out on 80 undamaged dry adult human crania, which were collected from the Anthropology Lab of Department of Anatomy, King George's Medical University, Lucknow, Uttar Pradesh, India. The age and gender of the bones used in the study is not known. Damaged skulls were excluded. We observed the skulls carefully to note variations in the hypoglossal canal or incidence of double hypoglossal canal and whether it was unilateral or bilateral.

\section{Results}

In this study wereport 18 cases (22.5\%) of double hypoglossal canal. We observed bilateral duplication of hypoglossal canal in 3 skulls (3.75\%). Unilateral duplication was seen in 15 skulls $(18.75 \%$ ) (7 on right side and 8 on left side).

\section{Discussion}

Lateral Various studies have been done in different populations in the past In a study, conducted on 40 skulls of Uttar Pradesh State of India by Zaidi SHH et al the incidence of double hypoglossal canal was reported to be $12.5 \%$ which is less than our findings i.e. $22.5 \%{ }^{[8]}$ They 
found bilateral double hypoglossal canal in 5\% cases and unilateral in $7.5 \%$ cases. Kaur $\mathrm{J}$ et al in their study of North Indian skulls reported double hypoglossal canal in $10.5 \%$ cases. ${ }^{[9]}$ Kanda $\mathrm{T}$ et al conducted a study on 590 Japanese patients by multislice computedtopography and found double hypoglossal canal in $16.9 \%$ of cases, which is nearer to our finding. ${ }^{[10]}$ They reported that $2.2 \%$ cases were bilateral and double hypoglossal canal was more common on left side than the right which is also the case in our study. This study reported bilateral duplication in $3.75 \%$ cases which is nearer to their findings.

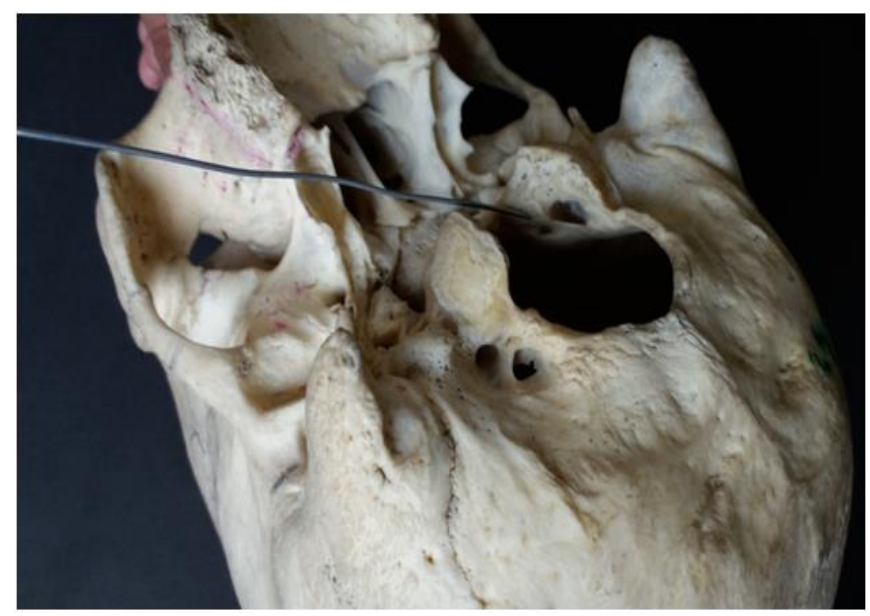

Figure 1: Duplicated left hypoglossal canal

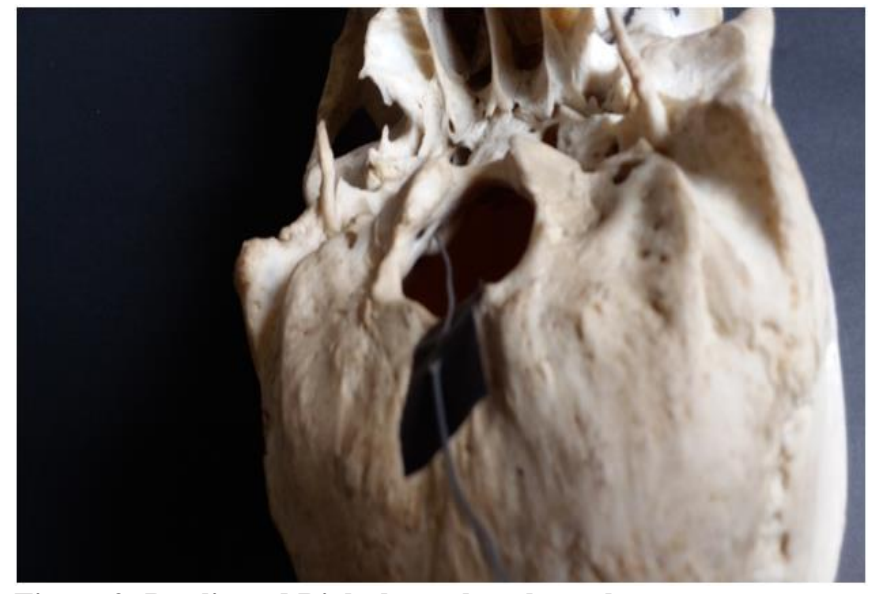

Figure 2: Duplicated Right hypoglossal canal

Osunwoke EA et al studied 79 dry skullsin Nigerian population out of which 55 were of male and 24 of females. ${ }^{[11]}$ They found double hypoglossal canal in $25.31 \%$ of cases, which is nearerto our findings. They reported that double hypoglossal canal was more common in male in comparison to female.

Jacob $\mathrm{M}$ et al studied 60 skull bones and observed double hypoglossal canal only in 12 skulls $(20 \%)$ out of which 4 were bilateral and in 8 were unilateral. ${ }^{[12]}$ In study conducted by Bhuller et al the hypoglossal canal was divided into two canals by a small bony spicule in $28.12 \%$ of cases. ${ }^{[13]}$ A study conducted by Fatima et al in Bihar, India double hypoglossal canal was present in $13.63 \%$ cases which is much less than our findings. They reported unilateral duplication in $7.27 \%$ and bilateral duplication in $6.36 \%$ of specimens. ${ }^{[14]}$ A case of bilateral internal triplication of hypoglossal canal was also reported by Raghunath $\mathrm{M}$ et al in India. ${ }^{[15]}$

Singh V et al studied 625 skulls and observed and classified the bridging pattern of hypoglossal canal. ${ }^{[16]}$ They classified the skulls having no bridging as Type 1; incomplete bridging as Type 2; complete endocranial bridging as Type 3; exocranial bridging as Type 4 and complete bridging throughout the canal as Type 5. They reported Type 1 category in $84 \%$ of skulls, Type 2 in $4.32 \%$ of cases with left side dominance. Type 3(a) category in $7.68 \%$ cases and Type 3(b) in $4.16 \%$ cases. They did not report any cases with Type 4 and Type 5 category.

\section{Conclusion}

The study of variant anatomy of the hypoglossal canal is of great importance to clinicians, anatomist, forensic experts, anthropologists and radiologists as the duplication of hypoglossal canal can result in minor degrees of alterations in movements of the tongue due to entrapment of nerve during ossification. A detailed morphometric study of hypoglossal canal is also required for the planning of surgical intervention around the base of skull.

\section{References}

1. Wysocki J, Kobryn H, Bubrowski M, Kwiatkowski J, Reymond J, Skarzynska B. The morphology of the hypoglossal canal and its size in relation to skull capacity in man and other species. Folia Morphol. 2004;63(1):11-7.

2. StandringSusan. Gray'sAnatomy.The Anatomical basis of clinical practice. 39th ed. Edinburg: Elsevier Churchill Livingstone. 2005, pp- 461.

3. Standring S. Head and Neck in grays anatomy: the anatomical basis of clinical practices, S. Standring, H. Ellis, J. C. Healy, D. Jhonson and A. Williams, Eds.; Churchill Livingtone, New York, USA, 40th ed; 2008:415:460.

4. Zaidi SHH, Gupta R, Usman N. A study of hypoglossal canal in north Indian crania. J Anat Soc India. 2011;60(2):224-6.

5. Canalis RF, Martin N, Black K, Ammirati M, Cheatham M, Bloch $\mathrm{J}$, et al. Lateral approach to tumors of the craniovertebral junction. Laryngoscope. 1993;103:343-9.

6. Schwaber MK, Netterville JL, Maciunas R. Microsurgical anatomy of the lower skull base a morphometric analysis. Am J Otol. 1990;11:401-5.

7. Tanzer A. Roentgen diagnosis of hypoglossal nerve canal. Radiol. 1975;18:42-8.

8. Zaidi SHH, Gupta R, Usman N. A study of hypoglossal canal in north Indian crania. J Anat Soc India. 2011;60(2):224-6.

9. Kaur J, Srivastava D, Singh D, Raheja S. The study of hyperostosic variants: significance of hyperostotic variants of human skulls in anthropology. Ana Cell Biol. 2012;45:268-73.

10. Kanda T, Kiritoshi T, Osawa M, Toyoda K, Oba H, Kotoku JI, et al. The incidence of double hypoglossal canal in Japanese: Evaluation with multislice computed tomography. PLoS ONE 2015;10(2):e0118317.

11. Osunwoke EA, Okoseimiema SC, Yorkhum KL, Uzomba GC. A study on the dimensions of hypoglossal canal in Southern Nigerian Crania. J BiolAgricult Health. 2014;4(4):78-81.

12. Jacob M, Avadhani R, Nair B, Nallathamby R, Soman MA. An original study on anatomical variations of hypoglossal canal. Int $\mathbf{J}$ Health Sci Res. 2014;4(12):339-41.

13. Bhuller A, Sanudo JR, Choi D, Abrahams PH. Intracranial course and relations of the hypoglossal nerve: an anatomic study. Surg Radiol Anat. 1998;20:109-12.

14. Fatima N, Rahman S, Akhtar MJ, Kumar V. Duplication of hypoglossal canal in North Indian human skulls.Int J Res Med 
Sci. 2017 Jun;5(6):2301-2304.

15. Raghunath M, Singh R, Shende N, Pandey S. Bilateral internal triplication of hypoglossal canal. Int $\mathrm{J}$ Health Sci Res. 2015;5(7):445-7.
16. Singh V, Sethi R, Kharb P, Singh R. Bridging pattern of hypoglossal canal - reclassified. J AnatSoci India. 2014;63(2):314.

Copyright: () the author(s), 2020. It is an open-access article distributed under the terms of the Creative Commons Attribution License (CC BY 4.0), which permits authors to retain ownership of the copyright for their content, and allow anyone to download, reuse, reprint, modify, distribute and/or copy the content as long as the original authors and source are cited.

How to cite this article: Yadav S, Pandey P, Pasricha N, Bhatnagar R. Variant Anatomy of Hypoglossal Canal: An Osteological Study in North Indian Population. Acad. Anat. Int. 2020;6(1):40-42.

DOI: dx.doi.org/10.21276/aanat.2020.6.1.9 